\title{
Peripheral arterial disease as seen on X-ray and arteriography
}

\author{
Antonio Lumbera Faltado, ${ }^{1}$ Mark Anthony Santiago Sandoval, ${ }^{1}$ Leoncio Kaw ${ }^{2}$
}

'Section of Endocrinology, Diabetes and Metabolism, Department of Medicine, Philippine General Hospital, University of the Philippines Manila, Manila, Philippines ${ }^{2}$ Section of Thoracic and Cardiovascular Surgery, Department of Surgery, Philippine General Hospital, University of the Philippines Manila, Manila, Philippines

Correspondence to Dr Antonio Lumbera Faltado Jr, aj_tons@yahoo.com

Accepted 3 November 2017

CrossMark

\section{To cite: Faltado $A L_{\text {, }}$} Sandoval MAS, Kaw L. BM Case Rep Published Online First: [please include Day Month Year]. doi:10.1136/ bcr-2017-221873

\section{DESCRIPTION}

An 80 -year-old woman was admitted for a 2 months history of non-healing ulcers on both feet. She is known to have type 2 diabetes, dyslipidaemia and hypertension for 30 years. She has a history of a femoral fracture on the left incurred after a fall 2 years ago for which she underwent open reduction and internal fixation.

On physical examination, there were ulcers on the lateral aspect of both feet and on the right malleolar area. Dorsalis pedis pulses were absent bilaterally.

An X-ray of both femurs was requested to check if the fracture healed properly and to rule out a new fracture since the patient remained bedridden despite surgery to correct the fracture. The X-ray revealed a metal implant on the left femur and with no new fracture. Incidentally, the femoral arteries were noted to be calcified along their entire length indicative of atherosclerosis (figure 1).

Aortography with bilateral lower extremity run-off was done to demonstrate patency of the arteries. This showed heavily calcified but patent common femoral, profunda femoris, superficial

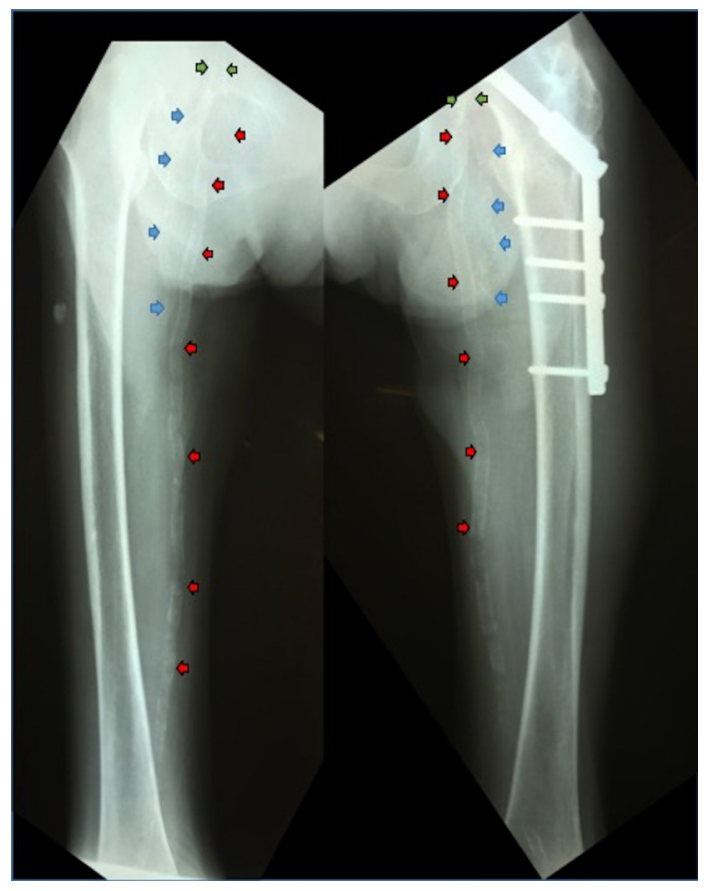

Figure 1 Lower extremity X-ray: calcified common femoral arteries (green arrows), deep femoral arteries (blue arrows) and superficial femoral arteries (red arrows).

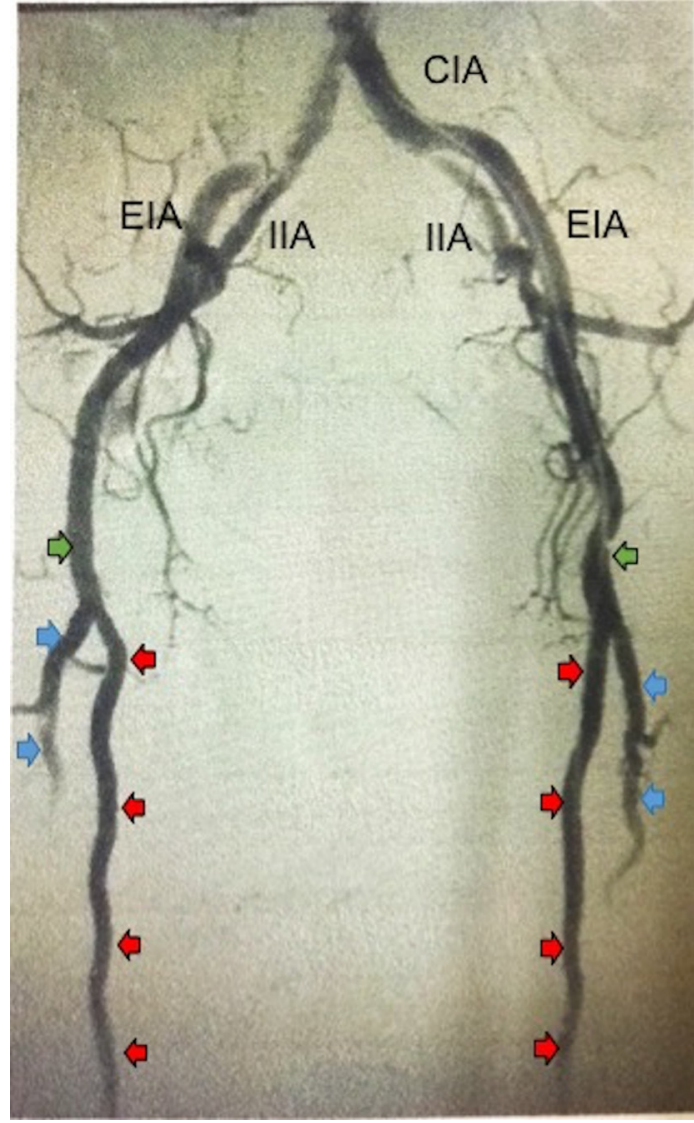

Figure 2 Bilateral lower extremity aortogram: common femoral arteries (green arrows), deep femoral arteries (blue arrows) and superficial femoral arteries (red arrows). CIA; Common Internal Iliac Artery, EIA; External Iliac Arteries, IIA ; Internal Iliac Arteries

femoral and popliteal arteries bilaterally (figure 2). Other pertinent findings were severely diseased and occluded anterior and posterior tibial arteries bilaterally. Both peroneal arteries were diseased but patent down to the distal leg.

The patient was managed medically with statin, aspirin, diabetes and antihypertensive medications. Local wound care was also provided.

Vascular calcification increases with age particularly in patients with hypertension, dyslipidaemia, chronic kidney disease and diabetes. From age 20 to 90 years, the incidence increases by $30 \%{ }^{1}$ Moreover, the presence of heavily calcified vessels as measured by calcium scoring using CT may be correlated with disease severity and outcomes such as coronary artery disease, amputations and all-cause mortality among patients with peripheral arterial disease (PAD). ${ }^{2}$ 
Although catheter angiography is considered the reference standard in the diagnosis of PAD, an easily available and non-invasive modality such as Doppler ultrasound that does not require the use of potentially nephrotoxic contrast agents can also be used. ${ }^{1}$ Calcification of peripheral vessels may cause a decrease in elastic recoil of the involved vessel, leading to diminished Doppler signals (ie, from a triphasic flow to a biphasic or monophasic flow pattern). ${ }^{34}$ Plain radiography on the other hand is a valuable but semiquantitative tool in the detection of vascular calcification.

\section{Learning points}

Atherosclerosis can symmetrically affect the arteries of the lower extremities.

- On this X-ray, we have seen both femoral arteries to be heavily calcified along their entire length.

- Even if the femoral arteries are heavily calcified on X-ray, they can still be found to be patent on arteriography.
Contributors ALFJ wrote the initial manuscript. MASS and LK contributed to the writing of the final version of the manuscript. LK performed the arteriogram. All were involved in the care of this patient.

Competing interests None declared.

\section{Patient consent Obtained.}

Provenance and peer review Not commissioned; externally peer reviewed.

(c) BMJ Publishing Group Ltd (unless otherwise stated in the text of the article) 2017. All rights reserved. No commercial use is permitted unless otherwise expressly granted.

\section{REFERENCES}

1 Rocha-Singh KJ, Zeller T, Jaff MR. Peripheral arterial calcification: prevalence, mechanism, detection, and clinical implications. Catheter Cardiovasc Interv 2014:83:E212-220

2 Shin HS, Jung Park M, Nyeo Jeon K, et al. Lower Extremity Arterial Calcification as a Predictor of Coronary Atherosclerosis in Patients with Peripheral Arterial Disease. Iran J Radiol 2016;13:e33179.

3 Verim S, Tasci I. Doppler ultrasonography in lower extremity peripheral arterial disease. Arch Turk Soc Cardiol 2013;41:248-55.

4 Hayden MR, Tyagi SC, Kolb L, et al. Vascular ossification-calcification in metabolic syndrome, type 2 diabetes mellitus, chronic kidney disease, and calciphylaxis-calcific uremic arteriolopathy: the emerging role of sodium thiosulfate. Cardiovasc Diabetol 2005:4:4

Copyright 2017 BMJ Publishing Group. All rights reserved. For permission to reuse any of this content visit

http://group.bmj.com/group/rights-licensing/permissions.

BMJ Case Report Fellows may re-use this article for personal use and teaching without any further permission.

Become a Fellow of BMJ Case Reports today and you can:

- Submit as many cases as you like

- Enjoy fast sympathetic peer review and rapid publication of accepted articles

- Access all the published articles

- Re-use any of the published material for personal use and teaching without further permission

For information on Institutional Fellowships contact consortiasales@bmjgroup.com

Visit casereports.bmj.com for more articles like this and to become a Fellow 